\title{
Ocular Fundus Abnormalities in Pre-Dialytic Chronic Kidney Disease Patients
}

\author{
Mohammad Kamrul Ahsan 1*, Muhammad Rafiqul Alam², Asia Khanam², A. H. Hamid Ahmed², \\ Md. Omar Faroque ${ }^{2}$, K. B. M. Hadiuzzaman², A. K. M. Shahidur Rahman², Rafi Nazrul Islam³, \\ Manik Chandra Mondal', Md. Azizur Rahman ${ }^{4}$
}

\author{
${ }^{1}$ Holy Family Red Crescent Medical College Hospital (HFRCMCH), Dhaka, Bangladesh \\ ${ }^{2}$ Department of Nephrology, Bangabandhu Sheikh Mujib Medical University (BSMMU), Dhaka, Bangladesh \\ ${ }^{3}$ Department of Nephrology \& Dialysis, BIRDEM General Hospital, Dhaka, Bangladesh \\ ${ }^{4}$ Bangladesh Eye Hospital \& Institute, Dhaka, Bangladesh \\ Email: *mkahsan2006@gmail.com
}

How to cite this paper: Ahsan, M.K., Alam, M.R., Khanam, A., Ahmed, A.H.H., Faroque, Md.O., Hadiuzzaman, K.B.M., Rahman, A.K.M.S., Islam, R.N., Mondal, M.C. and Rahman, Md.A. (2019) Ocular Fundus Abnormalities in Pre-Dialytic Chronic Kidney Disease Patients. Journal of Biosciences and Medicines, 7, 20-35. https://doi.org/10.4236/jbm.2019.711003

Received: September 24, 2019

Accepted: October 27, 2019

Published: October 30, 2019

Copyright $\odot 2019$ by author(s) and Scientific Research Publishing Inc. This work is licensed under the Creative Commons Attribution International License (CC BY 4.0).

http://creativecommons.org/licenses/by/4.0/

\begin{abstract}
Background: Chronic kidney disease (CKD) affects 10\% - 16\% of the adult population. Although ocular findings related to renal insufficiency include cataract, conjunctival calcification, lid edema, conjunctival pallor and xanthalesma, by far the most important is retinopathy. Objective: To evaluate the ocular fundus abnormalities in pre-dialytic chronic kidney disease patients of the adult population. Methodology: This cross-sectional observational study was conducted in the Department of Nephrology, Bangabandhu Sheikh Mujib Medical University (BSMMU), Dhaka, Bangladesh from April 2012 to March 2014. A total of 100 hospital admitted CKD patients were purposively selected for this study. Age, gender, blood pressure, Body Mass Index (BMI), 24 hours Urinary Total Protein (UTP), haemoglobin level, serum creatinine, serum cholesterol, serum triglyceride and color fundus photography findings of both eyes were recorded for each patient. Inter-group comparisons were made between patients with retinopathy and those without retinopathy. Results: Out of 100 adult non-dialytic CKD patients, 43 (43\%) had ocular fundus abnormalities, among them 27 (62.8\%) were male and 16 (37.2\%) were female. The risk of development of retinopathy was significantly higher among older patients $(\mathrm{p}=0.006)$, those with low haemoglobin level ( $\mathrm{p}$ $=0.0001)$ and high blood pressure. Retinopathy was significantly $(p=0.0001)$ increased with reduction of e-GFR. There was no relationship between BMI and high serum triglyceride level with retinal abnormality. Among 43 (43\%) patients with retinal abnormality, $30(69.76 \%)$ patients showed only hypertensive retinopathy and $5(11.6 \%)$ patients showed only diabetic retinopathy. Mixed hypertensive and diabetic retinopathy was found in 8 (18.6\%) patients.
\end{abstract}


Maculopathy was seen in 11 (25.58\%) patients, of whom 3 (6.98\%) had hypertensive retinopathy and $8(18.87 \%)$ had diabetic retinopathy. Optic atrophy was seen in $2(4.6 \%)$ patients and drusen like retinal deposits were seen in 2 (4.6\%) patients. Conclusion: Ocular fundus abnormalities are common among adult pre-dialytic CKD patients. Retinopathy is significantly higher in advanced stages of CKD.

\section{Keywords}

Chronic Kidney Disease (CKD), Ocular Fundus, Retinopathy

\section{Introduction}

Chronic kidney disease (CKD) is an irreversible and progressive process. It affects $10 \%-16 \%$ of the adult population in Asia, Australia, Europe and the United States [1]. CKD has been associated with many chronic conditions like anaemia, cardiovascular disease, bone and mineral disorder, dyslipidaemia, poor nutritional status, cognitive function etc. [2]. In some recent studies, it is also shown that, several types of ocular fundus abnormalities has been associated with CKD such as microvascular retinopathy, diabetic retinopathy, macular degeneration, retinal hemorrhage [3] [4]. Deterioration of vision in CKD is due to worsening of hypertensive or diabetic retinopathy, ischemic optic neuropathy, central retinal vein occlusion and cortical blindness [5]. At the time of end-stage renal disease (ESRD), $80.0 \%$ of patients developed secondary hypertension (HTN) [5]. Ocular abnormalities may be directly due to HTN, uremia and anaemia. Some are related to the causes leading to CKD.

In 1836, Richard Bright first discovered the association of renal disease with blindness. Later on, it was found that uremic retinitis is the manifestation of systemic hypertension [6]. A study among the Chinese population revealed that, the prevalence of overall ocular fundus pathology was 32\% in patients with CKD, and was significantly higher than that of patients without CKD [7]. Another study among 1904 CKD patients in the United States indicated that the overall prevalence of ocular fundus pathology among CKD patients was as high as $45 \%$ [ 8 ]. The prevalence of occular pathology varied with races, indicating effects of genetic and socioeconomic differences [8].

Retinal hemorrhage occurs in renal failure as microvascular and diabetic retinopathy, and of macular degeneration, which is exaggerated by the bleeding tendency in uremia [9] [10] [11]. Retinal microvascular abnormalities are common because hypertension, renovascular disease, and diabetes account for more than half of all patients with renal failure and also represent "traditional" risk factors for macrovascular and microvascular disease. "Non-traditional" risk factors such as inflammation, calcification, and endothelial dysfunction may contribute to the increased vascular risk too [12] [13] [14]. Diabetes is the single most common cause of CKD world-wide, and many patients with diabetes-asso- 
ciated renal failure also have retinopathy [15]. In addition, recent populationbased studies suggest that macular degeneration is increased in renal impairment. Risk factors common to renal failure and macular degeneration include increasing age, smoking, diabetes and hypertension [15].

Hypertensive retinopathic changes are particularly severe in renal failure. This has been attributed to the effects of retained nitrogen products. Accelerated hypertension can result in optic disc edema [16]. Blindness due to proliferative retinopathy or maculopathy is approximately five times more common in diabetic patients with nephropathy compared with normo-albuminuric patients [17]. Diabetic retinopathy tends to deteriorate with falling renal function, poorly controlled blood pressure and in patients whom no retinal treatment has been given before [18].

Retinopathy is often asymptomatic in its most treatable stage; delay in diagnosis can result in significant increase in the patient's risk of visual loss [19]. It is intended to highlight the importance of ocular examination to screen patients for any potential visual threat, so that necessary treatment and or advice can be given before they become irreversibly visually impaired. Therefore the aim of this study was to evaluate the ocular fundus abnormalities in pre-dialytic chronic kidney disease patients of adult population.

\section{Materials and Methods}

This hospital based cross sectional study was done in the Department of Nephrology, Bangabandhu Sheikh Mujib Medical University (BSMMU), Dhaka, Bangladesh from April 2012 to March 2014 to evaluate the ocular fundus abnormalities in pre-dialytic chronic kidney disease patients of adult population. The study was approved by the Ethical Review Committee, BSMMU, Dhaka, Bangladesh. According to the statistical calculation, a total of one hundred (100) pre-dialytic CKD patients were selected purposively.

Inclusion criteria was adult patients (age $>18$ years) of both sexes with any stage of CKD. Patient with clinical picture or investigations suggesting acute kidney injury (AKI), patient on maintenance haemodialysis, patient with renal transplant and patient with cataract were excluded from the study. Height, weight, blood pressure, other demographic, clinical and biochemical information were recorded in a pre-tested data sheets.

Laboratory investigations included complete blood count (CBC), serum creatinine, Urinary Total Protein (UTP), serum fasting lipid profile. Each patient's estimated glomerular filtration rate (e-GFR) was calculated by Cockcoft-Gault (CG) formula, and according to the e-GFR, patients were assigned different stages of CKD using ${ }^{*} \mathrm{KDIGO}, 2012$ guideline.

Patients were sent for color fundoscopy photograph of both eyes to department of Ophthalmology, BSMMU, Dhaka, Bangladesh. One image of each eye was taken after dilation with $0.5 \%$ tropicamide using a KOWA 7 (Canon, Tokyo, Japan) retinal camera. After that the color fundus photograph of each patient was assessed by an ophthalmologist in department of ophthalmology, BSMMU 
and comment was taken.

The participants were divided into two groups based on the presence or absence of retinopathy. The outcome variables analysed between the two groups were age, gender, blood pressure, BMI, Urinary Total Protein (UTP) in 24 hours, haemoglobin level, serum creatinine, serum cholesterol and serum triglyceride.

\subsection{Results of Fundus Examination Were Evaluated as Follows}

Retinopathy defined as vascular pathology as a result of diabetes, hypertension or other conditions. The presence of retinal microaneurysms only, dot and blot and/or flame hemorrhages only, hemorrhages and/or microaneurysms, cotton-wool spots, hard exudates, intra-retinal microvascular abnormalities, venous beading, arteriovenous nipping, new vessels on the disc and elsewhere, and pre-retinal and vitreous hemorrhages was defined as retinopathy. Arteriolar narrowing and arterio-venous nipping were also defined as retinopathy. Macular degeneration suggested by large drusen and pigmentary changes. Other fundus pathology, such as other macular abnormalities and optic nerve atrophy. "Any ocular fundus pathology" was defined by the presence of at least one of fundus abnormalities mentioned above.

\subsection{Definition of CKD}

According to ${ }^{\star}$ KDIGO 2012 Clinical Practice Guideline for the Evaluation and Management of Chronic Kidney Disease, CKD is defined as abnormalities of kidney structure or function, present for $>3$ months.

\subsection{Stages of CKD}

${ }^{*} \mathrm{KDIGO}$ suggested the following stages of CKD

- Stage 1: normal e-GFR $\geq 90 \mathrm{~mL} / \mathrm{min}$ per $1.73 \mathrm{~m}^{2}$.

- Stage 2: e-GFR between 60 to $89 \mathrm{~mL} / \mathrm{min}$ per $1.73 \mathrm{~m}^{2}$ (mildly decreased renal function).

- Stage 3a: e-GFR between 45 to $59 \mathrm{~mL} / \mathrm{min}$ per $1.73 \mathrm{~m}^{2}$ (Mild to moderately decreased renal function).

- Stage 3b: e-GFR between 30 to $44 \mathrm{~mL} / \mathrm{min}$ per $1.73 \mathrm{~m}^{2}$ (Moderate to severely decreased renal function).

- Stage 4: e-GFR between 15 to $29 \mathrm{~mL} / \mathrm{min}$ per $1.73 \mathrm{~m}^{2}$ (Severely decreased renal function).

- Stage 5: e-GFR of $<15 \mathrm{~mL} / \mathrm{min}$ per $1.73 \mathrm{~m}^{2}$ (Kidney failure). [ ${ }^{\star} \mathrm{KDIGO}=$ Kidney Disease Improving Global Outcomes $]$.

\subsection{Hypertensive Retinopathy Stages}

Hypertensive retinopathy is categorized into five (5) stages.

- Grade 0: No changes.

- Grade 1: Barely detectable arterial narrowing.

- Grade 2: Obvious arterial narrowing with focal irregularities. 
- Grade 3: Grade 2 plus retinal hemorrhages, exudates, cotton wool spots, or retinal edema.

- Grade 4: Grade 3 plus papilledema.

\subsection{Stages of Diabetic Retinopathy}

- Microaneurysms: The earliest clinical sign of diabetic retinopathy; these occur secondary to capillary wall outpouching due to pericyte loss; they appear as small, red dots in the superficial retinal layers.

- Dot and blot hemorrhages: Appear similar to microaneurysms if they are small; they occur as microaneurysms rupture in the deeper layers of the retina, such as the inner nuclear and outer plexiform layers.

- Flame-shaped hemorrhages: Splinter hemorrhages that occur in the more superficial nerve fiber layer.

- Retinal edema and hard exudates: Caused by the breakdown of the blood-retina barrier, allowing leakage of serum proteins, lipids, and protein from the vessels.

- Cotton-wool spots: Nerve fiber layer infarctions from occlusion of precapillary arterioles; they are frequently bordered by microaneurysms and vascular hyperpermeability.

- Venous loops and venous beading: Frequently occur adjacent to areas of nonperfusion; they reflect increasing retinal ischemia, and their occurrence is the most significant predictor of progression to proliferative diabetic retinopathy (PDR).

- Intraretinal microvascular abnormalities: Remodeled capillary beds without proliferative changes; can usually be found on the borders of the nonperfused retina.

- Macular edema: Leading cause of visual impairment in patients with diabetes.

\subsection{Statistical Analysis of Data}

Data cleaning validation and analysis was performed using the SPSS (Statistical Package for Social Science) software. Categorical data was presented as frequency, percentage and continuous variable was expressed as mean \pm SD (standard deviation). The statistics used to analyze the data were descriptive statistics and test done were Student's “t” test, Z-test, Chi-square test and Fisher exact test. The level of significance was set at 0.05 and $p$ value $<0.05$ was considered significant.

\section{Observations and Results}

To evaluate the pattern of ocular fundus abnormality in pre-dialytic CKD patients of different stages among the adult population, we have evaluated 100 patients (64 male and 36 female) and divided them into two groups: Group-A (with fundus abnormality being present; $n=43$, male $=27$, female $=16$ ) and Group-B (having no fundus abnormality; $\mathrm{n}=57$, male $=37$, female $=20$ ) (Table 1). 
Table 1. Basic data of the study patients.

\begin{tabular}{cccc}
\hline Parameters & $\begin{array}{c}\text { Group A } \\
(\mathbf{n}=43)\end{array}$ & $\begin{array}{c}\text { Group B } \\
(\mathbf{n}=57)\end{array}$ & P value \\
\hline Age (years) & & & \\
Mean \pm SD & $45.56 \pm 13.79$ & $37.46 \pm 14.46$ & $0.006^{* *}$ \\
Range & $20.00-73.00$ & $18.00-71.00$ & \\
Sex & & & \\
Male & $27(62.8)$ & $37(64.9)$ & $0.827^{* *}$ \\
Female & $16(37.2)$ & $20(35.1)$ & \\
BMI (kg/m $\left.{ }^{*}\right)$ & & & \\
Mean \pm SD & $21.97 \pm 3.53$ & $21.76 \pm 2.93$ & $0.740^{* *}$ \\
Range & $15.55-34.63$ & $15.20-30.61$ & \\
Systolic blood pressure (mmHg) & & & \\
Mean \pm SD & $141.40 \pm 23.46$ & $128.77 \pm 19.94$ & $0.005^{* *}$ \\
Range & $90.00-200.00$ & $90.00-170.00$ & \\
Range & & & \\
Diastolic blood pressure (mmHg) & & & \\
Mean \pm SD & $87.56 \pm 11.72$ & $81.40 \pm 11.75$ & $0.011^{*}$ \\
\hline
\end{tabular}

Group A: Ocular fundus abnormality present; Group B: Ocular fundus abnormality absent. Unpaired Student's " $t$ " test/Chi-square test was done to determine the level of significance: $n s=$ Not significant, ${ }^{*}=$ Significant $(\mathrm{p}<0.05),{ }^{* *}=$ Highly Significant $(\mathrm{p}<0.01)$.

The mean $( \pm \mathrm{SD})$ age of group-A (Ocular fundus abnormality present) was $45.56 \pm 13.79$, and that of group-B (Ocular fundus abnormality absent) was $37.46 \pm 14.46(\mathrm{p}=0.006)$. The difference was significant between these two groups $(\mathrm{p}=0.006)$ (Table 1$)$.

The mean $( \pm \mathrm{SD}) \mathrm{BMI}$ of the patients with retinopathy (group-A) was $21.97 \pm$ $3.53 \mathrm{~kg} / \mathrm{m}^{2}$ and the patients without retinopathy (group-B) was $21.76 \pm 2.93$ $\mathrm{kg} / \mathrm{m}^{2}$. The difference was not approaching to the level of significance $(\mathrm{p}=$ 0.740) (Table 1).

The mean $( \pm \mathrm{SD})$ systolic blood pressure in retinopathy positive group- $\mathrm{A}$ was $141.40 \pm 23.46(\mathrm{~mm}$ of $\mathrm{Hg}$ ) and that of group-B was $128.77 \pm 19.94(\mathrm{~mm}$ of $\mathrm{Hg})$, the difference was highly significant $(\mathrm{p}=0.005)$ (Table 1$)$.

The mean $( \pm \mathrm{SD})$ diastolic blood pressure in group-A was $87.56 \pm 11.72(\mathrm{~mm}$ of $\mathrm{Hg}$ ) and that of group-B was $81.40 \pm 11.75(\mathrm{~mm}$ of $\mathrm{Hg})$, the difference was statistically significant $(\mathrm{p}=0.011)$ (Table 1$)$.

Table 2(a) shows the laboratory investigation findings among the two groups. The mean $( \pm \mathrm{SD})$ haemoglobin level of patient with retinopathy (group-A) was $9.51 \pm 1.82 \mathrm{~g} / \mathrm{dl}$ and that of patients without retinopathy (group B) was $11.16 \pm$ $2.39 \mathrm{~g} / \mathrm{dl}$. The difference was highly significant $(\mathrm{p}=0.0001)$.

It was observed that, the mean $( \pm \mathrm{SD})$ urinary total protein (UTP) in patient with retinopathy (Group-A) was $2.47 \pm 2.06 \mathrm{~g} / 24$ hour and in patients without 
Table 2. (a) Laboratory investigation findings of the study patients; (b) Laboratory investigation findings of the study patients.

(a)

\begin{tabular}{|c|c|c|c|}
\hline Parameters & $\begin{array}{c}\text { Group A } \\
(\mathrm{n}=43)\end{array}$ & $\begin{array}{c}\text { Group B } \\
(\mathrm{n}=57)\end{array}$ & $P$ value \\
\hline \multicolumn{4}{|c|}{ Haemoglobin (g/dl) } \\
\hline Mean \pm SD & $9.51 \pm 1.82$ & $11.16 \pm 2.39$ & \multirow{3}{*}{$0.0001^{* *}$} \\
\hline \multirow[t]{2}{*}{ Range } & $5.80-15.10$ & $6.70-18.90$ & \\
\hline & No. (\%) & No. (\%) & \\
\hline$\geq 12.0 / 11.5$ (Male/Female) & $3(7.0)$ & $21(36.8)$ & \multirow{2}{*}{$0.001^{* *}$} \\
\hline$<12.0 /<11.5($ Male/Female $)$ & $40(93.0)$ & $36(63.2)$ & \\
\hline \multicolumn{4}{|c|}{ Urinary total protein $(\mathrm{g} / 24 \mathrm{~h})$} \\
\hline Mean \pm SD & $2.47 \pm 2.06$ & $4.16 \pm 3.25$ & \multirow{2}{*}{$0.003^{*}$} \\
\hline \multirow[t]{2}{*}{ Range } & $0.59-10.40$ & $0.18-12.60$ & \\
\hline & No. (\%) & No. (\%) & \\
\hline$\leq 0.3$ & $0(0.0)$ & $1(1.8)$ & \multirow{2}{*}{$1.000^{\star *}$} \\
\hline$>0.3$ & $43(100.0)$ & $56(98.2)$ & \\
\hline \multicolumn{4}{|c|}{ Serum creatinine $(\mu \mathrm{mol} / \mathrm{L})$} \\
\hline Mean \pm SD & $422.57 \pm 256.73$ & $196.52 \pm 161.55$ & \multirow{2}{*}{$0.0001^{\star *}$} \\
\hline \multirow[t]{2}{*}{ Range } & $84.00-1228.00$ & $62.00-961.10$ & \\
\hline & No. (\%) & No. (\%) & \\
\hline $60-120$ & $4(9.3)$ & $28(49.1)$ & \multirow{2}{*}{$0.0001^{* *}$} \\
\hline$>120$ & $39(90.7)$ & $29(50.9)$ & \\
\hline
\end{tabular}

Group A: Ocular fundus abnormality present; Group B: Ocular fundus abnormality absent; Unpaired Student's " $t$ " test/Chi-square test was done to determine the level of significance: $n s=$ Not significant, ${ }^{*}=$ Significant $(\mathrm{p}<0.05),{ }^{* *}=$ Highly Significant $(\mathrm{p}<0.01)$.

(b)

\begin{tabular}{|c|c|c|c|}
\hline Parameters & $\begin{array}{c}\text { Group A } \\
(\mathrm{n}=43)\end{array}$ & $\begin{array}{c}\text { Group B } \\
(\mathrm{n}=57)\end{array}$ & $P$ value \\
\hline \multicolumn{4}{|c|}{ Serum cholesterol $(\mathrm{mmol} / \mathrm{L})$} \\
\hline Mean \pm SD & $5.75 \pm 2.69$ & $8.18 \pm 3.28$ & \multirow{2}{*}{$0.0001^{\star *}$} \\
\hline \multirow[t]{2}{*}{ Range } & $2.40-13.70$ & $2.30-14.70$ & \\
\hline & No. (\%) & No. (\%) & \\
\hline $3.3-6.3$ & $21(48.8)$ & $12(21.1)$ & \multirow{2}{*}{$0.003^{*}$} \\
\hline \multirow[t]{2}{*}{$>6.3$} & $22(51.2)$ & $45(78.9)$ & \\
\hline & glyceride $(\mathrm{mn}$ & & \\
\hline Mean \pm SD & $3.05 \pm 1.76$ & $2.95 \pm 1.47$ & \multirow{2}{*}{$0.761^{* *}$} \\
\hline \multirow[t]{2}{*}{ Range } & $1.20-8.30$ & $1.20-7.60$ & \\
\hline & No. (\%) & No. (\%) & \multirow{3}{*}{$0.215^{\star *}$} \\
\hline$<2.3$ & $25(58.1)$ & $26(45.6)$ & \\
\hline \multirow[t]{3}{*}{$\geq 2.3$} & $18(41.9)$ & $31(54.4)$ & \\
\hline & Dyslipidaem & & \\
\hline & No. (\%) & No. (\%) & \\
\hline $\begin{array}{c}\text { Positive } \\
(\mathrm{TG} \geq 2.3 / \mathrm{S} . \text { Chol }>6.3)\end{array}$ & $29(67.4)$ & $47(82.5)$ & \multirow{2}{*}{$0.082^{\star *}$} \\
\hline $\begin{array}{c}\text { Negative } \\
(\mathrm{TG}<2.3 / \mathrm{S} . \text { Chol } \leq 6.3)\end{array}$ & $14(32.6)$ & $10(17.5)$ & \\
\hline
\end{tabular}

Group A: Ocular fundus abnormality present; Group B: Ocular fundus abnormality absent. Unpaired Student's "t" test/Chi-square test was done to determine the level of significance: $\mathrm{ns}=$ Not significant, ${ }^{*}=\mathrm{Sig}-$ nificant $(\mathrm{p}<0.05),{ }^{* *}=$ Highly Significant $(\mathrm{p}<0.01)$. 
retinopathy (Group-B) was $4.16 \pm 3.25 \mathrm{~g} / 24$ hour. The difference was statistically significant $(\mathrm{p}=0.003)$.

The mean $( \pm \mathrm{SD})$ serum creatinine of patient with retinopathy (Group-A) was $422.57 \pm 256.73 \mu \mathrm{mol} / \mathrm{L}$ and in patients without retinopathy (Group-B) was $196.52 \pm 161.55 \mu \mathrm{mol} / \mathrm{L}$. The difference was highly significant $(\mathrm{p}=0.0001)$.

The mean $( \pm \mathrm{SD})$ cholesterol level of group-A and group-B were $5.75 \pm 2.69$ $\mathrm{mmol} / \mathrm{L}$ and $8.18 \pm 3.28 \mathrm{mmol} / \mathrm{L}$ respectively, the difference was highly significant $(\mathrm{p}=0.0001)$. The mean $( \pm \mathrm{SD})$ triglyceride level of group-A and group- $\mathrm{B}$ was $3.05 \pm 1.76 \mathrm{mmol} / \mathrm{L}$ and $2.95 \pm 1.47 \mathrm{mmol} / \mathrm{L}$ respectively, the difference was not statistically significant $(\mathrm{p}=0.761)$. Among the patients with retinopathy (Group-A); 29 (67.4\%) had dyslipidaemia, and that was 47 (82.5\%) in patients without retinopathy (Group- $\mathrm{B})$, the difference was not significant $(\mathrm{p}=0.082)$ (Table 2(b)).

Table 3 shows different types of ocular fundus abnormalities. Among the 43 (43\%) patients with retinal abnormality, 30 (69.76\%) subjects showed only hypertensive retinopathy and $5(11.6 \%)$ subjects showed only diabetic retinopathy. Mixed hypertensive and diabetic retinopathy was found in $8(18.6 \%)$ subjects. Maculopathy was seen in 11 (25.58\%) subjects, among them 3 (6.98\%) patients with hypertensive retinopathy and $8(18.87 \%)$ patients with diabetic retinopathy. Optic atrophy was seen in $2(4.6 \%)$ patients and drusen like retinal deposit was seen in $2(4.6 \%)$ patients.

Table 4 shows the different types of hypertensive retinopathy. Among the 43 study subjects with retinal abnormality only hypertensive retinopathy was seen in $30(69.76 \%)$ patients, mixed hypertensive and diabetic retinopathy was found in $8(18.6 \%)$ patients. Among the total $38(88.37 \%)$ [30 patients with only hypertensive retinopathy plus 8 patient with mixed hypertensive and diabetic retinopathy] patients with hypertensive retinopathy; Grade-I hypertensive retinopathy was seen in 4 (9.3\%) patients, Grade-II hypertensive retinopathy was seen in 20

Table 3. Different types of ocular fundus abnormality $(n=43)$.

\begin{tabular}{cccc}
\hline Types of ocular fundus abnormality & Frequency & $\begin{array}{c}\% \text { among } \\
\text { total patients }\end{array}$ & $\begin{array}{c}\% \text { among } \\
\text { fundus } \\
\text { abnormality }\end{array}$ \\
\hline Total study patients & 100 & & \\
Ocular fundus abnormality & 43 & $30 \%$ & $69.76 \%$ \\
Only hypertensive retinopathy & 30 & $5 \%$ & $11.6 \%$ \\
Only diabetic retinopathy & 05 & $8 \%$ & $18.6 \%$ \\
Mixed hypertensive and diabetic retinopathy & 08 & $11 \%$ & $25.58 \%$ \\
Optic atrophy & $11(3 \& 8)^{*}$ & $2 \%$ & $4.6 \%$ \\
Retinal deposit & 02 & $2 \%$ & $4.6 \%$ \\
\hline
\end{tabular}

*Among 11 (25.58\%) maculopathy subjects, 3 (6.98\%) patients with hypertensive retinopathy and 8 $(18.87 \%)$ patients with diabetic retinopathy. NB: Some participants have more than one finding. 
Table 4. Different types of hypertensive retinopathy.

\begin{tabular}{cccc}
\hline Types of hypertensive retinopathy & Frequency & $\begin{array}{c}\% \text { among } \\
\text { total } \\
\text { retinopathy }\end{array}$ & $\begin{array}{c}\% \text { among } \\
{ }^{*} \text { HTN } \\
\text { retinopathy }\end{array}$ \\
\hline Total study patients & 100 & & \\
Total retinopathy & 43 & & \\
Total hypertensive retinopathy & 38 & $88.37 \%$ & $78.95 \%$ \\
Only hypertensive retinopathy & 30 & $69.76 \%$ & $10.52 \%$ \\
Grade-I hypertensive retinopathy & 04 & $9.3 \%$ & $52.63 \%$ \\
Grade-II hypertensive retinopathy & 20 & $46.51 \%$ & $28.95 \%$ \\
Grade-III hypertensive retinopathy & 11 & $25.58 \%$ & $7.89 \%$ \\
Grade-IV hypertensive retinopathy & 03 & $6.98 \%$ & $7.89 \%$ \\
Hypertensive retinopathy with maculopathy & 03 & $6.98 \%$ & $7.89 \%$ \\
Hypertensive retinopathy with optic disc swelling & 03 & $6.98 \%$ & $2.63 \%$ \\
\hline Hypertensive retinopathy with optic atrophy & 01 & $2.32 \%$ & \\
\hline
\end{tabular}

(46.51\%) patients, grade-III hypertensive retinopathy was in 11 (25.58\%) patients and $3(6.98 \%)$ patients were diagnosed as grade-IV hypertensive retinopathy. Maculopathy associated with hypertensive retinopathy was seen in $3(6.98 \%)$ patients. Hypertensive retinopathy with optic disc swelling was found in $3(6.98 \%)$ patients. Only $1(2.63 \%)$ patient with hypertensive retinopathy showed optic atrophy.

Table 5 shows the different types of diabetic retinopathy. Among the total 43 patients with retinopathy, diabetic retinopathy was seen in $13(30.23 \%)$ patients. Only diabetic retinopathy was seen in $5(11.6 \%)$ patients, mixed hypertensive and diabetic retinopathy was found in $8(18.6 \%)$ patients. Background non-proliferative diabetic retinopathy was seen in $8(61.54 \%)$ patients. Pre-proliferative diabetic retinopathy was observed in $2(15.38 \%)$ patients and proliferative diabetic retinopathy was found in $3(23.7 \%)$ patients. Diabetic maculopathy was seen in $8(61.54 \%)$ patients. And only 1 (7.69\%) patient with diabetic retinopathy showed optic atrophy.

Table 6 shows Ocular fundal findings in relation with estimated glomerular filtration rate (e-GFR). The mean $( \pm S D)$ e-GFR of patients with retinopathy positive was $22.98 \pm 18.16 \mathrm{ml} / \mathrm{min}$ per $1.73 \mathrm{~m}^{2}$, and those who do not have retinopathy was $50.69 \pm 24.95 \mathrm{ml} / \mathrm{min}$ per $1.73 \mathrm{~m}^{2}$. The difference was highly significant $(\mathrm{p}=0.0001)$. Thus it has been observed that retinopathy was significantly $(\mathrm{p}=0.0001)$ increased with reduction of e-GFR.

Table 7 shows the comparative study of retinal abnormalities in CKD stages 4 - 5 and CKD stage $1-3$. Here it has been observed that, among the total 43 subjects with retinal abnormalities, $32(74.4 \%)$ was in CKD stage 4-5, and 11 (25.6\%) in CKD stage $1-3(\mathrm{p}=0.006)$. Among the total 30 patients with hypertensive retinopathy; 23 (76.7\%) patients were in CKD stage $4-5$ and 7 (23.3) 
Table 5. Different types of diabetic retinopathy.

\begin{tabular}{cccc}
\hline Types of diabetic retinopathy & Frequency & $\begin{array}{c}\% \text { among } \\
\text { total } \\
\text { retinopathy }\end{array}$ & $\begin{array}{c}\% \text { among } \\
\text { diabetic } \\
\text { retinopathy }\end{array}$ \\
$\begin{array}{c}\text { Total study patients } \\
\text { Total retinopathy }\end{array}$ & 100 & & \\
Total diabetic retinopathy & 43 & & \\
Only diabetic retinopathy & 13 & $30.23 \%$ & \\
Both diabetic and hypertensive Retinopathy & 08 & $11.63 \%$ & $38.46 \%$ \\
Background non-proliferative diabetic retinopathy & 08 & $18.6 \%$ & $61.54 \%$ \\
Pre-proliferative diabetic retinopathy & 02 & $4.65 \%$ & $15.38 \%$ \\
Proliferative diabetic Retinopathy & 03 & $6.98 \%$ & $23.06 \%$ \\
Diabetic retinopathy with Maculopathy & 08 & $18.6 \%$ & $61.54 \%$ \\
Diabetic retinopathy with optic atrophy & 01 & $2.32 \%$ & $7.69 \%$ \\
\hline
\end{tabular}

NB: Some participants have more than one finding.

Table 6. Ocular fundal findings in relation with estimated glomerular filtration rate (e-GFR)

\begin{tabular}{cccc}
\hline e-GFR $\left(\mathrm{ml} / \mathrm{min}\right.$ per $\left.1.73 \mathrm{~m}^{*}\right)$ & Group A $(\mathrm{n}=43)$ & Group B $(\mathrm{n}=57)$ & P value \\
\hline Mean \pm SD & $22.98 \pm 18.16$ & $50.69 \pm 24.95$ & $0.0001^{* *}$ \\
Range & $5.47-76.00$ & $7.39-88.89$ & \\
Stage 1, 2(e-GFR $\geq 60)$ & No. (\%) & No. (\%) & \\
Stage 3 (e-GFR 30 - 59) & $4(9.3)$ & $26(45.6)$ & \\
Stage 4 (e-GFR 15 - 29) & $7(16.3)$ & $14(24.6)$ & $0.0001^{* *}$ \\
Stage 5 (e-GFR < 15) & $21(48.8)$ & $11(19.3)$ & \\
\hline
\end{tabular}

Group A: Ocular fundus abnormality present; Group B: Ocular fundus abnormality absent. Unpaired Student's " $\mathrm{t}$ " test/Chi-square test/Fisher's exact test. ${ }^{* *}=$ Highly significant $(\mathrm{p}<0.01)$.

Table 7. Comparison of retinal abnormalities in CKD stages 4 - 5 and CKD stage 1-3 ( $\mathrm{n}=$ 43).

\begin{tabular}{ccccc}
\hline Parameters & n & $\begin{array}{c}\text { Stage 4 - 5 } \\
\text { No. (\%) }\end{array}$ & $\begin{array}{c}\text { Stage 1 - 3 } \\
\text { No. (\%) }\end{array}$ & P value \\
\hline Retinal abnormality & 43 & $32(74.4)$ & $11(25.6)$ & $0.006^{*}$ \\
Only hypertensive retinopathy & 30 & $23(76.7)$ & $7(23.3)$ & $0.006^{*}$ \\
Only diabetic retinopathy & 5 & $3(60.0)$ & $2(40.0)$ & $0.625^{* *}$ \\
Mixed hypertensive plus diabetic retinopathy & 8 & $4(50.0)$ & $4(50.0)$ & $1.000^{* *}$ \\
\hline
\end{tabular}

Z-test; $\mathrm{ns}=$ Not significant; ${ }^{*}=$ Significant at $\mathrm{p}<0.05$.

patients were in CKD stage $1-3(\mathrm{p}=0.006)$. On the other hand, among the 5 patients with only diabetic retinopathy; $3(60 \%)$ patients were in CKD stage 4 - 5 and $2(40 \%)$ patients were in CKD stage $1-3(\mathrm{p}=0.625)$. Among eight (8) pa- 
tients with both hypertensive and diabetic retinopathy; 4 (50\%) patients were in CKD stage 4 - 5 and rest $4(50 \%)$ patients were in CKD stage $1-3$ ( $\mathrm{p}=1.00)$. Retinopathy was significantly higher in advanced stages of CKD (stage 4 - 5) compared to early stages (stage 1 - 3).

\section{Discussion}

Chronic kidney disease (CKD) affects different organs of the body including eye. To find out the ocular fundus abnormalities in CKD patients, we had evaluated 100 hospital admitted patients in Department of Nephrology, BSMMU, Dhaka, Bangladesh, who had not yet commenced dialysis.

A recent study by Bixia and Ling et al. among the Chinese population revealed that the prevalence of overall ocular fundus pathology was $32 \%$ in patients with CKD and was significantly higher than that of patients without CKD [7]. Also similar study Grunwald and Alexander et al. among 1904 CKD patients in the United States showed that the overall prevalence of ocular fundus pathology was as high as $45 \%$ [8]. In this study, out of 100 CKD patients, 43 (43\%) patients showed ocular fundus abnormality. Therefore this finding has got similarity with studies mentioned above.

In the CRIC (Chronic Renal Insufficiency Cohort) study by Grunwald and Alexander et al. showed that male have significantly higher retinopathy than female (male $=48.10 \%$, female $=42.15 \%, \mathrm{p}<0.05$ ) [8]. In this current study, 64 (64\%) patients were male and $36(36 \%)$ were female. Among the 64 male patients, $27(62.8 \%)$ patients and among the 36 female patients, $16(37.2 \%)$ patients showed ocular fundus abnormalities. Thus there was no significant difference ( $\mathrm{p}$ $=0.827$ ) between male and female in development of retinopathy in this study.

In two different studies by Alexander et al. [8] and another Tien et al. [20], both observed retinopathy was high in older age groups. In this series, the mean $( \pm \mathrm{SD})$ age of retinopathy positive and retinopathy negative patients were $45.56 \pm$ 13.79 years and $37.46 \pm 14.46$ years respectively and $p=0.006$, which showed similarity with previous study. Therefore it has been documented that retinopathy is higher in older age groups.

Bixia and Ling et al. showed significantly high BMI in patients with retinopathy [7]. Another study by Grunwald et al. showed significantly low BMI in patients with retinopathy [8]. In this current study, BMI showed no significant difference $(p=0.740)$ between retinopathy positive and retinopathy negative groups. So relationship between BMI with retinopathy remains unexplained.

Bixia et al. reported that, both systolic and diastolic blood pressures were significantly higher in patients with retinopathy than those who had no retinopathy [7]. In this current study, the mean $( \pm S D)$ systolic blood pressure was significantly higher in patients with retinopathy than patients without retinopathy $(141.40 \pm 23.46 \mathrm{~mm}$ of $\mathrm{Hg}$ and $128.77 \pm 19.94 \mathrm{~mm}$ of $\mathrm{Hg}, \mathrm{p}=0.005)$. Similarly the mean $( \pm S D)$ diastolic blood pressure was significantly higher in patients with retinopathy than patients without retinopathy $(87.56 \pm 11.72 \mathrm{~mm}$ of $\mathrm{Hg}$ and $81.40 \pm 11.75 \mathrm{~mm}$ of $\mathrm{Hg}, \mathrm{p}=0.011)$. Thus similar results were observed between 
the current and previous studies.

In this study, low hemoglobin level was strongly associated with development of retinopathy. The hemoglobin level in retinopathy positive group was $9.51 \pm$ $1.82 \mathrm{~g} / \mathrm{dl}$, and retinopathy negative group was $11.16 \pm 2.39 \mathrm{~g} / \mathrm{dl}$, and the $\mathrm{p}$ value was 0.0001 , which was highly significant. Qiao et al. in Finland studied on 1691 diabetic patients and found that, the diabetic patients with hemoglobin level lower than $12 \mathrm{mg} / \mathrm{dl}$ were two times more likely to develop diabetic retinopathy [21]. So the finding of our study was consistent with this previous study.

Proteinuria was found to be independently associated with retinopathy, which further supports that both retinopathy and proteinuria are markers of systematic microvascular abnormalities [7]. This association has also been found to exist among participants without hypertension or diabetes, suggesting that susceptibility to microvascular disease may be caused by mechanisms other than those directly stemming from hypertension or diabetes [7]. We had found the mean $( \pm \mathrm{SD})$ urinary total protein (UTP) in patients with retinopathy was $(2.47 \pm 2.06$ $\mathrm{g} / 24$ hour$)$, which was significantly lower $(\mathrm{p}=0.003)$ than patients without retinopathy ( $4.16 \pm 3.25 \mathrm{~g} / 24 \mathrm{hour})$. It may be due to sclerosis of renal vasculature in advanced stages of CKD. Therefore the association between proteinuria and retinopathy was not observed in this current study.

Current study showed that high serum creatinine levels associated with retinal abnormalities. The mean $( \pm S D)$ serum creatinine of patient with retinopathy $(422.57 \pm 256.73 \mu \mathrm{mol} / \mathrm{L})$ was significantly higher $(\mathrm{p}=0.0001)$ than patients without retinopathy $(196.52 \pm 161.55 \mu \mathrm{mol} / \mathrm{L})$ in this study. The possible explanation for this retinopathy-kidney link might be; the retinal microvascular abnormalities resulting from diabetes, hypertension, cigarette smoking, inflammation and other processes that provide a common pathophysiologic link for the development and progression of CKD [20] [22]. Grunwald et al. showed that, the prevalence of retinopathy was significantly higher among participants with CKD, compared with participants without CKD [8].

Evaluation of lipid profile showed that, the mean $( \pm \mathrm{SD})$ cholesterol level of retinopathy positive and retinopathy negative patients were $5.75 \pm 2.69 \mathrm{mmol} / \mathrm{L}$ and $8.18 \pm 3.28 \mathrm{mmol} / \mathrm{L}$ respectively. It may be due to the maximum glomerulonephritis patients with proteinuria was in the group with no retinopathy. The mean triglyceride level of group-A and group-B was $3.05 \pm 1.76 \mathrm{mmol} / \mathrm{L}$ and $2.95 \pm 1.47 \mathrm{mmol} / \mathrm{L}$, the difference was not statistically significant $(\mathrm{p}=0.761)$. Dyslipidaemia was found in 29 (67.4\%) patients with retinopathy (Group-A) and that was $47(82.5 \%)$ patients without retinopathy (Group-B), the difference was not significant $(\mathrm{p}=0.082)$. However in a study by Tien and Josef et al. documented that, retinopathy was associated with high cholesterol levels and higher triglyceride levels [20].

In this study, 43 patients showed retinal abnormality. Of them $30(69.76 \%)$ patients showed only hypertensive retinopathy and 5 (11.63\%) patients showed only diabetic retinopathy. $8(18.60 \%)$ patients had both hypertensive and diabetic changes on their ocular color fundal examination. Optic atrophy was seen in 2 
(4.65\%) patients and drusen like retinal deposit was seen in $2(4.65 \%)$ patients.

Among the 38 (30 patients with hypertensive retinopathy plus 8 patient with mixed hypertensive and diabetic retinopaty) patients with hypertensive retinopathy, the most common abnormality we had found was grade-II hypertensive retinopathy $(20,46.51 \%)$, then grade-III $(11,25.58 \%)$ and grade-I hypertensive retinopathy $(4,10.52 \%)$ respectively. The least we found was grade-IV hypertensive retinopathy $(3,6.98 \%)$. Soft exudates which was due to hypertensive retinopathy found in $32.55 \%(\mathrm{n}=14)$ patients. Maculopathy was seen in $3(6.98 \%)$ patients. Only 1 patient $(2.32 \%)$ with hypertensive retinopathy showed optic atrophy.

Among the 13 patients of diabetic retinal abnormality, 5 patients (11.63\%) with only diabetic retinopathy, 8 patients $(18.60 \%)$ showed combination of both diabetic and hypertensive retinopathy. Majority of those [ 8 patients $(18.60 \%)$ ] had non-proliferative background diabetic retinopathy, 2 patients (4.65\%) showed pre-proliferative diabetic retinopathy and 3 patients $(6.98 \%)$ showed vision threatening proliferative diabetic retinopathy with neovascularisation. Microaneurysm, which was the hallmark of diabetic retinopathy was found in $30.23 \%$ ( $n=$ 13 among total 43 patients with retinopathy) patients. More than half of the patients $61.54 \%(\mathrm{n}=8)$ showed diabetic maculopathy. Optic atrophy was seen in $7.69 \%(n=1)$ patients with diabetic retinopathy.

In a study by Rajeev and Mohamad et al. showed that 41 (41 of 149, 28\%) patients with CKD stages 3 to 5 had a moderate to severe diabetic retinopathy, compared with $16(11 \%)$ patients with CKD stages 1 to $2(\mathrm{p}=0.001)$ [23]. In addition, diabetic retinopathy became more common as renal function deteriorated in CKD stages 3 to $5(\mathrm{p}=0.001)$. But they did not found any difference in level of hemoglobin A1c in patients with diabetic retinopathy with CKD stages 3 to 5 compared with $\mathrm{CKD}$ stages 1 to $2(7.9 \% \pm 1.81 \%$ and $8.5 \% \pm 2.34 \%$, respectively, $\mathrm{p}=0.30$ ) [23]. They also reported that proliferative diabetic retinopathy were more common in CKD stages 3 to 5 than CKD stages 1 to 2 (18 of $149,12 \%$ compared with 2 of $150,1 \%, \mathrm{p}=0.001)$ and similarly became more common as renal function deteriorated $(\mathrm{p}=0.001)$. In this present study, diabetic retinopathy in CKD stage 1 - 3 and CKD stage 4 - 5 had no significant statistical difference.

Maculopathy in current study was seen in 11 (25.58\%) patients, of them 3 (6.98\%) were associated with hypertensive retinopathy and 8 (18.6\%) were diabetic maculopathy. In a study [23], it was observed that macular degeneration was increased in patients with CKD stages 3 to 5 compared with patients with CKD stages 1 to 2 . They had seen 62 (62 of 140,44\%) patients with CKD stages 3 to 5 had these changes compared with 43 (43 of 148, 29\%) patients with CKD stages 1 to $2(\mathrm{p}=0.010)$.

Grunwald and Alexander et al. observed that, lower e-GFR was associated with a much higher incidence of fundus pathology [8]. The percentage of participants with any eye pathology was $60 \%$ in those with e-GFR $<30 \mathrm{ml} / \mathrm{min}$ and $35 \%$ in participants with e-GFR $\geq 50 \mathrm{ml} / \mathrm{min}$ [8]. In the current study, it has 
been observed that, the mean $( \pm S D)$ e-GFR of patients with retinopathy positive was $22.98 \pm 18.16 \mathrm{ml} / \mathrm{min}$ per $1.73 \mathrm{~m}^{2}$ which was significantly lower $(\mathrm{p}=0.0001)$ than those who do not have retinopathy $\left(50.69 \pm 24.95 \mathrm{ml} / \mathrm{min}\right.$ per $\left.1.73 \mathrm{~m}^{2}\right)$. The low e-GFR was a risk factor for development of retinopathy as retinopathy significantly increases with decreasing e-GFR. Therefore this current study concluded that retinopathy was significantly $(\mathrm{p}=0.0001)$ higher in advanced stages of CKD than in early stages.

\section{Conclusion}

The current study suggests that, ocular fundus abnormalities are common among the pre-dialytic CKD patients of adult population. It has been observed that retinopathy is significantly higher in advanced stages of CKD than in early stages. Hypertensive retinopathy, non-proliferative diabetic retinopathy, vision threatening proliferative diabetic retinopathy and maculopathy are not uncommon in adult pre-dialytic CKD patients.

\section{Limitations of Study}

It was a single centre study with relatively small sample size.

\section{Recommendations}

To identify the correct incidence of retinopathy in pre-dialytic chronic kidney disease (CKD) patients in adult population, a large scale, multi-center study will be needed. Regular ocular follow up, early recognition of abnormality and intervention will provide better visual outcome.

\section{Conflicts of Interest}

The authors declare no conflicts of interest regarding the publication of this paper.

\section{References}

[1] Matsushita, K., vandervelde, M., Astor, B.C., Woodward, M., Levey, A.S., de Jong, P.E., Coresh, J. and Gansevoort, R.T. (2010) Association of Estimated Glomerular Filtration Rate and Albuminuria with All-Cause and Cardiovascular Mortality in General Population Cohorts: A Collaborative Meta-Analysis. The Lancet, 375, 2073 2081. https://doi.org/10.1016/S0140-6736(10)60674-5

[2] Go, A.S., Chertow, G.M., Fan, D., McCulloch, C.E. and Hsu, C.Y. (2004) Chronic Kidney Disease and the Risks of Death, Cardiovascular Events, and Hospitalization. New England Journal of Medicine, 351, 1296-1305. https://doi.org/10.1056/NEJMoa041031

[3] Evans, R.D. and Rosner, M. (2005) Fellows' Forum: Ocular Abnormalities Associated with Advanced Kidney Disease and Hemodialysis. Seminars in Dialysis, 18, 252-257. https://doi.org/10.1111/j.1525-139X.2005.18322.x

[4] Patel, D.V., Snead, M.P. and Satchi, K. (2002) Retinal Arteriolar Calcification in a Patient with Chronic Renal Failure. The British Journal of Ophthalmology, 86, 1063. https://doi.org/10.1136/bjo.86.9.1063 
[5] Stein, J.H., Hulton, J.J. and Kohler, P.O. (1990) Internal Medicine. 3rd Edition, Little Brown \& Company, New York, 809-810.

[6] Duke-Elders, S. and Dohree, J.H. (1967) System of Ophthalmology. The CV Mosby Company, London, 315-347.

[7] Gao, B., Zhu, L., Pan, Y., Yang, S., Zhang, L. and Wang, H. (2011) Ocular Fundus Pathology and Chronic Kidney Disease in a Chinese Population. BMC Nephrology, 12, 62. https://doi.org/10.1186/1471-2369-12-62

[8] Grunwald, J.E., Alexander, J., Maguire, M., Whittock, R., Parker, C., McWilliams, K., Lo, J.C., Townsend, R., Gadegbeku, C.A., Lash, J.P. and Fink, J.C. (2010) Prevalence of Ocular Fundus Pathology in Patients with Chronic Kidney Disease. Clinical Journal of the American Society of Nephrology, 5, 867-873. https://doi.org/10.2215/CJN.08271109

[9] Wong, T.Y. and Mitchell, P. (2004) Hypertensive Retinopathy. New England Journal of Medicine, 351, 2310-2317. https://doi.org/10.1056/NEJMra032865

[10] Early Treatment Diabetic Retinopathy Study Research Group (1991) Grading Diabetic Retinopathy from Stereoscopic Color Fundus Photographs-An Extension of the Modified Airlie House Classification: ETDRS Report Number 10. Ophthalmology, 98, 786-806. https://doi.org/10.1016/S0161-6420(13)38012-9

[11] Seddon, J.M., Sharma, S. and Adelman, R.A. (2006) Evaluation of the Clinical Age-Related Maculopathy Staging System. Ophthalmology, 113, 260-266. https://doi.org/10.1016/j.ophtha.2005.11.001

[12] Arici, M. and Walls, J. (2001) End-Stage Renal Disease, Atherosclerosis, and Cardiovascular Mortality: Is C-Reactive Protein the Missing Link? Kidney International, 59, 407-414. https://doi.org/10.1046/j.1523-1755.2001.059002407.x

[13] Obialo, C.I. (2007) Cardiorenal Consideration as a Risk Factor for Heart Failure. The American Journal of Cardiology, 99, S21-S24. https://doi.org/10.1016/j.amjcard.2006.12.016

[14] Zoccali, C. (2006) Traditional and Emerging Cardiovascular and Renal Risk Factors: An Epidemiologic Perspective. Kidney International, 70, 26-33.

https://doi.org/10.1038/sj.ki.5000417

[15] Liew, G., Mitchell Wong, T.Y., Iyengar, S.K. and Wang, J.J. (2008) CKD Increases the Risk of Age-Related Macular Degeneration. American Society of Nephrology, 19, 806-811. https://doi.org/10.1681/ASN.2007080844

[16] Donald, J. and Gass, M. (1992) Bullous Retinal Detachment and Multiple Retinal Pigment Epithelial Detachments in Patients Receiving Hemodialysis. Graefés Archive for Clinical and Experimental Ophthalmology, 230, 454-458. https://doi.org/10.1007/BF00175933

[17] Gabriel, R. (1990) Renal Medicine. 3rd Edition, WB Sanders, London, 26-47.

[18] Pahor, D., Hojs, R. and Gračner, B. (1995) Conjunctival and Corneal Changes in Chronic Renal Failure Patients Treated with Maintenance Hemodialysis. Ophthalmologica, 209, 14-16. https://doi.org/10.1159/000310567

[19] Albert, D.M., Jacobiec, F.A., Azar, D.T., Gragoudas, E.S., Power, S.M. and Robinson, N.L. (2000) Principles and Practice of Ophthalmology, Volume II. 2nd Edition, WB Saunders, Philadelphia, PA, 1900-1913.

[20] Wong, T.Y., Coresh, J., Klein, R., Muntner, P., Couper, D.J., Sharrett, A.R., Klein, B.E., Heiss, G., Hubbard, L.D. and Duncan, B.B. (2004) Retinal Microvascular Abnormalities and Renal Dysfunction: The Atherosclerosis Risk in Communities Study. Journal of the American Society of Nephrology, 15, 2469-2476.

[21] Qiao, Q., Keinänen-Kiukaanniemi, S. and Läärä, E. (1997) The Relationship be- 
tween Hemoglobin Levels and Diabetic Retinopathy. Journal of Clinical Epidemiology, 50, 153-158. https://doi.org/10.1016/S0895-4356(96)00335-6

[22] Edwards, M.S., Wilson, D.B., Craven, T.E., Stafford, J., Fried, L.F., Wong, T.Y., Klein, R., Burke, G.L. and Hansen, K.J. (2005) Associations between Retinal Microvascular Abnormalities and Declining Renal Function in the Elderly Population: The Cardiovascular Health Study. American Journal of Kidney Diseases, 46, 214 224. https://doi.org/10.1053/j.ajkd.2005.05.005

[23] Deva, R., Alias, M.A., Colville, D., Tow, F.K., Ooi, Q.L., Chew, S., Mohamad, N., Hutchinson, A., Koukouras, I., Power, D.A. and Savige, J. (2011) Vision-Threatening Retinal Abnormalities in Chronic Kidney Disease Stages 3 to 5. Clinical Journal of the American Society of Nephrology, 6, 1866-1871.

https://doi.org/10.2215/CJN.10321110 